\title{
Mapping Organizational Culture Schemes Based on Correlational Class Analysis
}

\author{
Luciano Rossoni ${ }^{l}$, Clayton Gonçalves, Mônica Pereira da Silva, Alex Ferreira Gonçalves
}

Universidade do Grande Rio, Brasil

\begin{abstract}
Organizational culture tends to be investigated based on organizational consensus degree, even when it is seen as shared meanings. However, sharing meanings does not imply having the same opinions. On the contrary, there may be agreement on which cultural elements are relevant, even when opinions differ from each other, a fact that enables individuals to share cultural schemes, although they disagree with each other's answers. Recent advancements in the cultural cognition field have enabled the present tutorial article to map organizational culture schemes based on correlational class analysis. This method divides the sample into scheme classes by listing respondents based on the linear dependence degree between answers given to a questionnaire, rather than on agreement between respondents. The aim of this tutorial article is to use a scale of organizational values adapted to the Brazilian context in order to map cultural schemes based on a survey conducted with 207 workers from different companies. Results point toward two different scheme classes (reactive and resilient) that condition the effect of attitudes and organizational structure on employee appreciation and satisfaction. Besides providing a tutorial on how to use the investigated technique, the study points out its relevance for organizational culture field.
\end{abstract}

Keyword: correlational class analysis, belief systems, shared meanings, organizational values, cultural schemes.

\section{Mapeando Esquemas da Cultura Organizacional por Meio da Análise de Classes Correlacionais}

\section{Resumo}

A cultura organizacional, mesmo quando vista como significados compartilhados, tende a ser investigada a partir do grau de consenso organizacional. Todavia, compartilhar significados não implica em dizer que as opiniões são as mesmas. Pelo contrário, pode haver concordância em quais elementos culturais são relevantes, mesmo que as opiniões divirjam. Isso remete à possibilidade de indivíduos compartilharem esquemas culturais mesmo que discordem das respostas. Avanços recentes no campo da cognição cultural permitiram, neste artigo tutorial, mapear os esquemas da cultura organizacional por meio da análise de classes correlacionais. Tal método divide a amostra em classes de esquemas, elencando os respondentes por meio do grau de dependência linear entre respostas em um questionário, não pela concordância. A partir de uma survey com 207 trabalhadores de diferentes companhias, nós utilizamos uma escala de valores organizacionais adaptada ao contexto brasileiro para mapear os esquemas culturais. Os resultados apontam para duas classes distintas de esquemas (reativos e resilientes), que condicionam o efeito de atitudes e da estrutura organizacional na valorização e satisfação dos funcionários. Além de fornecermos um tutorial de uso da técnica, nós apontamos sua relevância para os estudos sobre cultura organizacional.

\footnotetext{
${ }^{1}$ The authors would like to thank CNPq (Process 435946 / 2018-8) and FAPERJ (Process E-26 / 203.238 / 2017) for their financial resources. The first author is deeply indebted to John Mohr (in memorian), who was a great supporter of the use of relational methods such as CCA.
} 
Palavras-chave: análise de classes correlacionais, sistemas de crenças, significados compartilhados, valores organizacionais, esquemas culturais.

\section{Introduction}

Exploring the concept of organizational culture based on shared meaning schemes has been used as a relevant line of investigation in organizational studies (Miranda, Kim, \& Summers, 2015; Oberg, Korff, \& Powell, 2017; Smircich, 1983). It happens because organizational culture schemes can affect organizations' behavior, since they are shared mental representations of what organizations mean in terms of beliefs, values and attitudes (Harris, 1994; Langfield-Smith, 1992; Wood, Stoltz, Van Ness, \& Taylor, 2018). Cultural schemes condition everything - from the most ideal things such as the concept of strategic visions (Aktaş, Çiçek, \& Kiyak, 2011) to material issues such as group work (LangfieldSmith, 1992). However, even when studies take into consideration individual and group levels within organizations (Harris, 1994), most of them aim at understanding cultural schemes based on consensus degree (Basov \& Brennecke, 2017; Garro, 2000; Hofstede, Neuijen, Ohayv, \& Sanders, 1990; Obert et al., 2017) and ignore their multivocality and heterogeneity (DiMaggio, Sotoudehb, Goldberg, \& Shepherd, 2018; Goldberg, 2011).

The fundamental matter about such consensual approaches to organizational culture lies on the fact that they suffer from conceptual and methodological issues. In conceptual terms, it is necessary emphasizing that organizational actors who share the same meaning scheme do not necessarily have the same opinion about something (Goldberg, 2011; Hunzaker \& Valentino, 2019). In fact, sharing cultural schemes means that individuals agree with judgment criteria, even if their opinions are totally different from each other (Rawlings \& Childress, 2019). These judgments are not based on isolated assessments, but on assessments and judgments that, in their turn, form complex meaning networks (Emirbayer, 1997; Mohr \& White, 2008). In methodological terms, conventional statistical and analytical methods were not capable of capturing cultural schemes, since they did not take into account two principles, namely: relationality, whose meanings and attitudes do not emerge from entities in isolation, but from relationships between them; and multiplicity, according to which respondents organize themselves into groups based on simultaneous patterns of similarity and divergence between opinions (DiMaggio et al., 2018).

In light of these conceptual and methodological challenges, Goldberg (2011) has developed a technique called relational class analysis (RCA) in order to capture shared meanings through relationships between answers given to a particular questionnaire. This technique uses a measure called relationality to compare respondents based on patterns of association among all answers, rather than on individual answers. It has been recurrently used in studies about cultural taste (Goldberg, 2011; Daenekindt, 2017), public opinion (Baldassarri \& Goldberg, 2014; Wu, 2014) and organizational innovation (Miranda et al., 2015) Boutyline and Vaisey (2017) have pointed out a series of formalization and accuracy issues in RCA, which led Boutyline (2017) to develop an improved method capable of capturing meaning schemes based on the correlation between respondents' choices. This method, which is called correlational class analysis (CCA), has already been used in different fields such as public opinion (Barbet, 2020; Daenekindt, Koster, \& Van der Waal, 2017; Hunzaker, \& Valentino, 2019) and consumption of cultural products (Daenekindt, 2019; Rawlings \& Childress, 2019). Although RCA and CCA were developed to capture cultural schemes, the literature in the field lacks studies focused on using these methods to map organizational culture. 
In order to fill this gap, the current tutorial article used correlational class analysis (CCA) to map organizational cultural schemes without hurting cultural principles such as relationality and multiplicity. CCA was operationalized through the corclass package in the $R$ software, whose application is detailed in the readme.pdf file. It was applied to a survey conducted with 207 workers from different companies, based on a scale of organizational values adapted to the Brazilian context, which was developed by Ferreira, Assmar, Estol, Helena and Cisne (2002). First, analyses conducted in the current study have pointed toward two different classes, which were called reactive and resilient schemes. These classes did not operate as predictor variables; however, since they showed different covariance structures between respondents' attitudes, they revealed effects that would have been ignored in the full sample and that would not have been captured through any other grouping method. It is worth emphasizing the importance of identifying correlational classes by showing that each class has its own equifinality, i.e., the effect of organizational variables and attitudes towards organizational values affect employees' appreciation and satisfaction in a different way.

Assumingly, CCA application can be useful for three reasons. First, although research about shared meaning schemes has gained prominence in cultural studies (Hunzaker \& Valentino, 2019; Rawlings \& Childress, 2019), it has been ignored in organizational studies, despite the acknowledgement that organizational culture manifests itself through shared schemes (Harris, 1994; Miranda et al., 2015). Second, the method introduced in the current study enables a quantitative way of capturing shared meanings that go beyond the mere agreement between respondents - something that has been already captured by cluster analysis (Boutyline, 2017; DiMaggio et al., 2018). Indeed, new hypotheses can be outlined in the management field in order to open ways to investigations that go beyond the study of cultural schemes. Third, as CCA application was already detailed in a tutorial, the learning curve can be significantly shortened, thus increasing its use potential.

The current tutorial article was structured in four different sections. The first section presents the fundamentals of correlational class analysis (CCA), whose basis lies on the concept of shared meaning schemes. In order to do so, its original method, relational class analysis (RCA), as well as corrections and formalizations promoted by Boutyline (2017) in CCA development were defined. The second section presents data collection procedures and specifies the operation of the scale applied to organizational values, which was used as application example. The third section runs the CCA by pointing out how scheme classes are generated and how they can be defined, as well as specifies the steps to be taken to reproduce the analyses. In addition, it shows that the CCA method is totally different from cluster analysis. The study sample is divided based on the two identified classes - reactive and resilient -; two regression models are used to show how each scheme conditions the effect of organizational and attitudinal variables on employee appreciation and satisfaction. Finally, the fourth section discusses the results and presents the advantages and implications of using correlational class analysis to capture organizational phenomena.

\section{Fundamentals of Correlational Class Analysis}

Schemes are complex structures of mental representations (Goldberg, 2011), either innate or acquired through experience and acculturation (Zerubavel, 1997), which organize knowledge about reality (Strauss \& Quinn, 1997). They play a key role in cultural analysis because individuals' world experiences are understood through them (DiMaggio, 1997; Hunzaker \& Valentino, 2019). In fact, thinking about culture as schemes leads individuals to imagine that although culture is embodied by individual cognitive structures, it also 
reflects socialization and information exchange processes at collective sphere, whose meanings tend to be shared. Hence, the usefulness of thinking about shared meaning schemes, since they simultaneously reside in individuals as cognitive trait and in the collective as reference frames (Wood et al., 2018).

However, saying that individuals can share meaning schemes does not mean that they agree with each other or that they have the same opinion about a given subject (Goldberg, 2011). It means that they share judgment parameters embedded in complex meaning networks (Emirbayer, 1997; Mohr \& White, 2008) that attribute similar relevance and significance to a given topic. Thus, the meaning given to any particular element is not based on its isolated assessment, but on its reference to other elements (DiMaggio et al., 2018). For example, individuals may disagree on the legality of abortion, but they can use the same reason to justify their opinion, namely: the religious one. In this case, they differ in opinion, but they converge on reasons. Therefore, their schemes tend to be similar, despite their discrepancy of opinions.

Capturing shared meaning schemes has always been a methodological challenge due to their relational and multivocal nature (Boutyline, 2017; Goldberg, 2011), mainly when one aims at making their structures intelligible, while preserving the heterogeneity inherent to such schemes (Boutyline \& Vaisey, 2016; DiMaggio et al., 2018). Therefore, comparing how individuals organize their schemes requires examining associations among their attitudes, rather than the attitudes themselves. Thus, it is necessary developing a methodological approach capable of capturing schemes based on relationships between answers given to a questionnaire, since the same answer can have different meanings (DiMaggio et al., 2018).

Relational methods, such as social network analysis, are a viable analytical alternative to capture the structure of relationships between parties. Recent advancements in such methods have made it possible capturing these relationships based on different weights (e.g., correlation between items in a given questionnaire), as well as using such weighted relationships as input to define groups of variables; thus, they enabled the development of two class estimation methods, namely: the relational class analysis (Goldberg, 2011) and the correlational class analysis (Boutyline, 2017).

\section{Relational Class Analysis (RCA)}

The Correlational Class Analysis (CCA) developed by Boutyline (2017) is the methodological approach of choice in the current tutorial article. This method is based on Goldberg's (2011) seminal study on shared schemes. Thus, the current section will make a previous presentation of Goldberg's (2011) Relational Class Analysis (RCA) method to help better understanding the relational and correlational class approach.

According to Goldberg (2011), traditional methods focused on investigating the concept of heterogeneity in multivariate data fail on two main points: 1) they group respondents by comparing their answers in an independent way and by ignoring the association among variables; 2) they overall assess associations between the attitudes of all respondents, without taking into consideration that respondents may have different association patterns. Thus, traditional methods address only one dimension of the relationship between variables (multidimensional scale and factor analysis) or between individuals (cluster analysis).

In addition to analyzing classes of individuals who share similar ideas, RCA uses relationality, which is a measurement created by Goldberg (2011), to compare these individuals based on patterns of relationships between their attitudes, rather than on their attitudes themselves. Thus, Goldberg (2011, p. 1399) conceptualizes relationality as "the 
extent to which two individuals show similar pattern of association between measures of opinion about issues associated with a specific social domain".

RCA is applicable to a variety of investigations about population heterogeneity, since it is capable of detecting classes presenting different patterns of relationship between variables (Goldberg, 2011). Thus, RCA aims at analyzing individuals who think in a similar way by separating them into classes that share the same meaning schemes (Baldassarri \& Goldberg, 2014). In order to do so, it uses algorithms to maximize the modularity between variables in order to define classes. However, despite the great advancement provided by the method developed by Goldberg (2011), Boutyline (2017) has questioned RCA accuracy in mapping cultural schemes.

\section{Correlational Class Analysis (CCA): an improved method}

Boutyline (2017) has highlighted some inconsistencies in the RCA method. The first one refers to lack of a formal definition to indicate how a group of respondents shares a cultural scheme. On the other hand, Goldberg (2011) has illustrated RCA's intuition in a graph (Figure 1), which represented the musical taste of 4 respondents: $A, B, C$ and $D$. Each respondent pointed out how much they like a given music style; their choices ranged from 1 (strongly dislike) to 5 (strongly like).

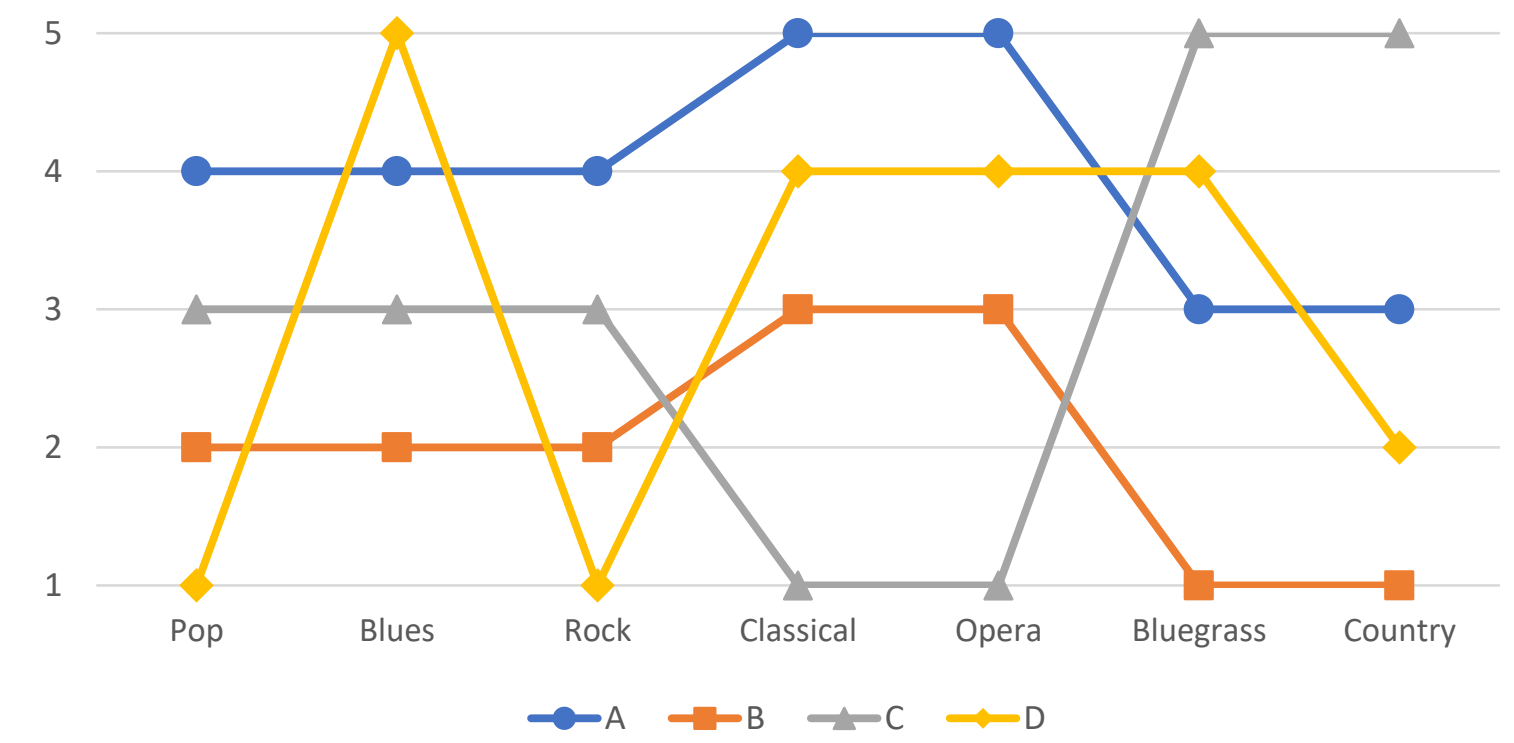

Figure 1 - Musical taste of four respondents

Note: Each line represents the choices made by each respondent, which ranged from 1 (strongly dislike) to 5 (strongly like). Source: reproduced from Goldberg (2011, p. 1405) and Boutyline (2017, p. 357).

Based on the answers, one can infer the schematic similarity between each respondent. Boutyline (2017) presents the algebraic operations that represent them. While respondent A likes pop music, blues and rock and roll, he strongly likes classical music and opera and is indifferent to bluegrass and country music: $A=[4,4,4,5,5,3,3]$. On the other hand, $B$ dislike pop music, blues and rock, he is indifferent to classical music and opera and he strongly dislikes bluegrass and country music: $B=[2,2,2,3,3,1,1]$. Despite their different choices, $A$ and $B$ have the same pattern, according to which $B=A-2$, since $B$ assessed all musical genres in the same descending degree (-2) as $A$. Therefore, $A$ and $B$ are schematically identical. Respondent $C$, in his turn, is indifferent to pop music, blues and rock and roll, he strongly dislikes classical music and opera and he strongly likes bluegrass and country music: $C=[3,3,3,1,1,5,5]$. According to Boutyline (2017), $C$ presents the same relative pattern as $A$ and $B$; however, all choices are vertically $[C=2(-1) A+11)]$ or 
equivalently shifted, inverted and amplified $[C=2(-1) B+7]$. Finally, respondent $D$ i strongly likes pop music and rock and roll, he strongly likes blues, likes classical music, opera and bluegrass, and dislikes country music: $D=[1,5,1,4,4,4,2]$. Unlike the other respondents, $D$ opposes bluegrass and country, but he does not oppose bluegrass and opera. Thus, as Boutyline (2017) points out, no inversion, multiplication or change of pattern can bring him closer to $A, B$ and $C$. Therefore, it is possible saying that $D$ follows a scheme different from the others.

Based on this example, Boutyline (2017) proposed that two respondents have exactly the same scheme if: i) their answers are identical $(Y=X)$; ii) their answers are exactly inverse $(Y=-X)$; iii) their answers are uniformly more extreme $(Y=k X)$; iv) the answers given by one are uniformly more positive than those given by the other $(Y=X+b)$; and v) any combination of conditions ii, iii and iv. Based on these conditions, it is possible inferring that "two respondents $(X$ and $Y$ ) follow exactly the same scheme if, and only if, there is a linear transformation capable of producing a vector of responses from the other or, more formally, if there are constants $b$ and $k \neq 0$, wherein $Y=k X+b$ " (Boutyline, 2017, p. 357). Thus, based on Boutyline (2017), it is possible inferring that two actors present greater schematic similarity when the existence of both $k$ and $b$ is maximized, either in the functional form or through approximations.

As previously mentioned, Goldberg (2011) has proposed a schematic similarity measure called relationality $\mathrm{R} i j$, wherein $R$ is the measure of similarity between $i$ and $j$, which ranges from -1 to 1 . Since extreme values indicate the same scheme, relationality operates with absolute values $\mid$ Rij|. However, according to Boutyline (2017), Goldberg (2011) has developed a measure of relationality based on the arithmetic difference between schemes, which is not an adequate way to capture schematic similarity. This issue leads to another RCA deficiency, i.e., the lack of accuracy in capturing shared schemes.

Given this limitation, Boutyline (2017) has advocated that it is necessary finding another measure of schematic similarity capable of preserving the same conditions, i.e., $X$ and $Y$ follow the same scheme if there are constants $b$ and $k \neq 0$, wherein $Y=k X+b$. If one takes into consideration that $X$ and $Y$ have finite variation other than zero, as well as conditions according to which $X$ and $Y$ do not show variance in the answers, then $k \neq 0$. Thus, a measure appears to be appropriate when it takes into consideration that two respondents are schematically closer to each other when they are linearly more dependent on one another, as in the case of Pearson's correlation (Boutyline, 2017).

Boutyline (2017) has compared the results of his newly created measure (CCA) to RCA based on Pearson's correlation between respondents. CCA produced a much better result than RCA in a sample comprising 800 respondents, who have been originally investigated by Goldberg (2011). CCA superiority over RCA was also proven through the simulation of 5,000 samples from the same data bank. Boutyline (2017) used the Normalized Mutual Information (MNI) test, which measures the accuracy of network partition algorithms, and found CCA adjustment equal to 0.97 (the maximum value is 1), whereas RCA adjustment was 0.74. CCA was the most accurate in all conditions in simulations of schematic relationships other than the linear ones. Finally, the author has analyzed whether sample partition into groups was more informative than the full sample - he used structural equation modeling (SEM) to analyze multiple groups. Results of the Akayke and Schwarz tests have indicated that both RCA and CCA were more accurate than the full sample; however, CCA was more accurate than the RCA.

Thus, given the analytical superiority of CCA over RCA, as well as its greater coherence with the formalization of shared cultural schemes, the current study used correlational class analysis to capture organizational culture schemes. 


\section{Data and Measurements}

Data were collected in a sample of workers from different companies at the metropolitan region of Curitiba (PR) to enable analyzing their organizational culture schemes - these workers were the observation unit. The sample was selected by convenience; data were collected through the application of a closed questionnaire, whose questions investigated employees' attitudes towards the organizational values they work in, as well as a series of information about organizations and individuals. Thirty-seven (37) collaborators were properly trained in order to apply five to ten questionnaires in different organizations. Thus, data collection process resulted in 246 answered questionnaires (6.6 questionnaires per collection agent, on average). However, some of these questionnaires presented biased answers, as well as a large number of unanswered questions, which resulted in the exclusion of 11 of them. In addition, 28 cases were excluded because the correlational class analysis technique does not allow treating missing values (Boutyline, 2017). Thus, the final sample comprised 207 cases.

\section{Capturing Organizational Culture}

Contemporary theories about culture assume that it is formed based on shared meanings (Goldberg, 2011; Mohr \& White, 2008), whose cultural schemes emerge from individuals' cognitive appreciation of social reality (DiMaggio, 1997; Strauss \& Quinn, 1997; Wood et al., 2018; Zerubavel, 1997). It would not be different for organizational culture, whose cultural schemes emerge from workers' appreciation about the organization (Langfield-Smith, 1992). Thus, it is necessary capturing organizational culture based on attitudinal scales in order to preserve the heterogeneity and multivocality of cultural schemes (DiMaggio et al., 2018).

Choice was made to evaluate organizational culture based on values, although acknowledging the existence of other elements such as beliefs, myths and artifacts (Schein, 1992), which are the ones most directly representing cultural schemes. Among different alternatives for the operation of organizational values, the current study has adopted scales already validated and used in Brazil - which is the current research context -, based on the premise that they would enable greater face validity (Netemeyer, Bearden, \& Sharma, 2003). First, the current study took into consideration the scales by Gomide Jr. and Martins (1997) and Tamayo and Gondim (1996), which are among the most cited studies in this field; however, the instrument used in the study by Gomide Jr. and Martins (1997) did not necessarily include cultural elements. The study by Tamayo and Gondim (1996), on the other hand, worked with items that were not sufficiently described, a fact that limited its ability to assess the set of values.

Given the limitations in these scales, choice was made to operationalize organizational values based on constructs identified by Ferreira et al. (2002), who measured a total of 55 items using a 5-point Likert scale, whose measurement ranged from "it does not apply to my company in any way" to "it totally applies to my company". The aforementioned authors used studies conducted by Calori and Sarnin (1991) and Hofstede et al. (1990) to substantiate the questions of a semi-structured questionnaire, whose goal was to identify values and organizational practices among business executives in Rio de Janeiro City.

Ferreira et al. (2002) have identified four dimensions corresponding to the values: cooperative professionalism (23 items); hierarchical structure rigidity (13 items); competitive and individualistic professionalism ( 8 items); employee satisfaction and well- 
being (11 items). Although having these four previously defined dimensions at hand, we made another attempt to identify dimensionality based on principal component analysis due to several indications of divergence between factors deriving from empirical evaluations conducted in different cultural contexts (Calori \& Sarnin, 1991; Hofstede et al. 1990).

Similar to Ferreira et al. (2002), factors were herein extracted based on principal component analysis. First, their adequacy was evaluated through Kaiser-Meyer-Olkin $(\mathrm{KMO}=0.886)$ and Bartlett's sphericity tests $(p<0.001)$, which presented satisfactory results. Next, the number of factors was evaluated based on the scree plot method, which pointed toward four dimensions that met the number identified by Ferreira et al. (2002); however, there was $47.5 \%$ total variance explained - this value was higher than the $34 \%$ found Ferreira et al. (2002). Still, based on Ferreira et al. (2002), the four factors were subjected to Varimax orthogonal rotation, as well as to oblique (Oblimin) rotation, in order to improve factor loading interpretation. The items fit to each of the factors in an identical way, in both rotation methods. Thus, the Varimax rotation output, which is easier to be interpreted, was used in the current study. Items presenting factor loading lower than 0.4 were excluded from the study, as suggested by Hair, Black, Babin and Anderson (2018). Finally, the reliability of the analyzed dimensions was analyzed through Cronbach's alpha test; items reducing such reliability were discarded, whereas alpha values greater than 0.7 were considered reliable (see Nunnaly's criterion, 1978). The scale was reduced to 47 items, which were grouped into four factors (one for each dimension of the organizational values) using arithmetic mean (see items, codes and factor loading in Appendix A of the readme.pdf file).

Table 1 presents the four herein identified factors, which did not show the same distribution found by Ferreira et al. (2002), although the current study followed all procedures adopted by them. It happened because the answer pattern identified in the companies investigated in Curitiba City was different from the study carried out in Rio de Janeiro City, a fact that was already expected due to the change of context. Two factors could be interpreted in the same way, namely: cooperative professionalism and employee satisfaction and appreciation. However, competition and hierarchical rigidity formed a single factor in the current study. Meritocratic professionalism was not assessed in the study by Ferreira et al. (2002), but it stood out as a factor in the present analysis.

Table 1 - Descriptive Statistics and Correlations among Organizational Value Dimensions

\begin{tabular}{|c|c|c|c|c|c|c|c|}
\hline & $\begin{array}{c}\text { Item } \\
\mathrm{s}\end{array}$ & Mean & $\begin{array}{c}\text { Variance } \\
\%\end{array}$ & $\begin{array}{c}\text { Cronbach } \\
\text { Alpha }\end{array}$ & (2) & (3) & (4) \\
\hline $\begin{array}{l}\text { 1. Cooperative Professionalism } \\
\text { 2. Hierarchical Rigidity and }\end{array}$ & 17 & 3.7 & 15.9 & 0.93 & $-.393 * *$ & $.647 * *$ & $.609 * *$ \\
\hline $\begin{array}{l}\text { Competition } \\
\text { 3. Employee Appreciation and }\end{array}$ & 13 & 3.0 & 12.8 & 0.90 & & $-.376^{* *}$ & $-.202 * *$ \\
\hline Satisfaction & 10 & 3.2 & 11.8 & 0.92 & & & $.597 * *$ \\
\hline 4. Meritocratic Professionalism & 7 & 3.3 & 7.0 & 0.77 & & & \\
\hline
\end{tabular}

Note: $* * \mathrm{p}<0.01, \mathrm{n}=207$

The first factor covered elements associated with the appreciation of aspects such as collaboration, creativity, initiative, acceptance of organization's ideals, professionalism as a virtue, among others. Together, these aspects suggested the designation of cooperative professionalism to this factor, which comprised 17 items, whose variance explained was $15.9 \%$ and Cronbach's alpha was 0.93. The second factor comprised 13 items whose expressed values were almost opposite to the first factor: no stimulus or reward to creativity and initiative, promotion limited to the formal structure and, mainly, incentive to 
competition. These aspects were used to name the factor as hierarchical rigidity and competition, whose variance explained was $12.8 \%$ and alpha was 0.90 . The third factor comprised 10 items, which were mainly associated with concern with employees' well-being and satisfaction, and the association between such satisfaction and productivity. This factor was called employee appreciation and satisfaction, whose variance explained was $11.8 \%$ and alpha was 0.92 . Finally, the last factor refers to values close to the first one; however, they emphasize aspects such as commitment to the company and competence as promotion means in the organization - this factor was called meritocratic professionalism and encompassed 7 items whose variance explained was $7 \%$ and alpha was 0.77 .

\section{Correlational Class Analysis Application}

Organizational culture schemes were mapped based on the 47 items comprising the organizational values scale by Ferreira et al. (2002) in order to illustrate the usefulness of correlational class analysis. The items are available in the Organizational_Culture_CCA.sav database, which, in its turn, is available in the supplementary material of the current tutorial article. With respect to data structure, both Goldberg (2011) and Boutyline \& Vaisey (2017) assume that variables used in relational and correlational classes: a) must be ratio or interval variables; b) preferably show the same measurement level; c) present linear association with each other; and d) have reliable dimensions. However, both Boutyline (2017) and DiMaggio et al. (2018) used low reliability scales, which had different measurement levels and were based on binary variables. Nevertheless, Boutyline (2017) has demonstrated that RCA and CCA were robust methods when such assumptions were not met, as well as when associations between variables were not linear. In most cases, CCA performance in creating classes was better than that of RCA, mainly when the assumptions were met - which was the case of current data.

Correlational class analysis (CCA) becomes operational through the corclass package (Boutyline, 2017) in the $R$ software, whose installation instructions, as well as the definition of additional packages necessary to follow this tutorial, are available at the readme.pdf file, which, in its turn, is available in the supplementary material section of this tutorial paper. Codes, functions and parameters necessary to run this tutorial are also described there; they were herein omitted to make result explanation easier. Thus, it is strongly recommended reading the readme.pdf file, whose steps must be followed to enable effective CCA application. Anyway, the current tutorial indicates the part of the readme.pdf file where each analysis presented in the text was generated.

The results were divided into four different stages. First, correlational classes were generated in order to divide the sample into two categories of individuals who presented different belief schemes about organizational culture. Second, these classes were defined based on visual techniques of social network analysis and on heat maps generated in the previous stage. Third, it was demonstrated that classes empirically differ from clusters to avoid confusion with other database partitioning techniques. Fourth, it was shown how correlational classes can operate as distinction schemes; two regression models, one for each class, were run to enable seeing how effects between them can be different.

\section{Generating Relational Classes}

Based on the 47 items comprising the organizational values scale, CCA has divided the sample into two correlational classes (see step 5 in the readme.pdf file): one comprising 105 cases $(50.7 \%)$; the other one, $102(49.3 \%)$. As previously stated, correlational classes are not clusters, although they classify individuals. Thus, there is no judgment homogeneity on organizational values. Therefore, describing the mean of each class for each item would 
be poorly informative. CCA aims at aggregating individuals who agree about the relevant arguments or items, although they do not agree with each other. Consequently, classes aggregate members who present similar choice patterns between each pair of variables, which, in the present case, refer to the 47 items in the scale. This procedure leads to increased covariance within each class; thus, analyzing the correlation matrices of each relational class can be more productive (Goldberg, 2011).

However, large matrices are not very intuitive when it comes to interpreting systems of variables because they require powerful graphic resources. Since the network metaphor fits very well the assumptions and intuitions of belief and value systems, these classes are often represented through social network analysis graphs (Boutyline \& Vaisey 2017; DiMaggio et al., 2018; Goldberg, 2011). Figure 2 depicts the correlation matrix generated for each class based on a network graph (step 5.1 of the readme.pdf file). Each node in the network refers to an item in the scale; the edges point toward significant correlation between each item and edge thickness represents the correlation degree. In addition, the heat map for each correlation matrix was plotted (step 5.2 of the readme.pdf file). Intense blue frames indicate strongly positive correlations, whereas intense red frames indicate negative correlations. Low and moderate correlations are represented in lighter shades.
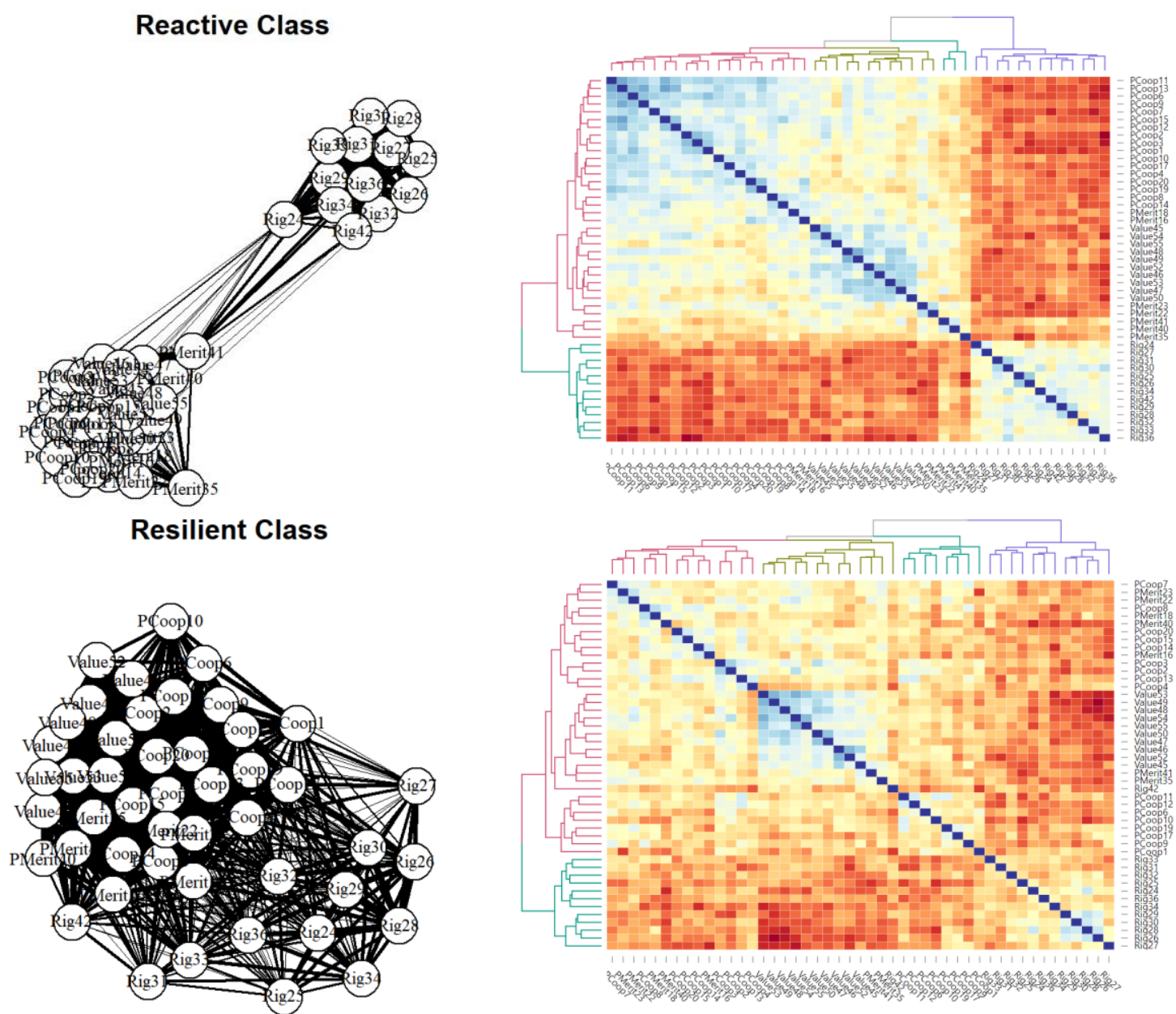

Figure 2 - Relational Class Network Diagrams and Heat Maps

Note: Nodes in the graphs represent each item in the scale. Loops represent significant correlation between variables $(\mathrm{p}<0.05)$; the thicker the loop, the stronger the correlation. Negative relations were omitted to improve visualization, although they were used to define classes (step 5.1 in the readme.pdf file). Significant negative correlations are highlighted in red on the heat maps, significant positive correlations are highlighted in blue, whereas low and moderate correlations are highlighted in different shades of yellow (step 5.2 in the 
readme.pdf file). Supplementary material (Organizational_Culture_Classes.html) presents an interactive heat map.

\section{Defining Correlational Classes}

In order to give sense to correlational classes, each of them was defined based on the analysis of correlation patterns between items by taking the four organizational-value dimensions as reference. The first relational class was called Reactive Schemes. Far from creating any taxonomy of cultural schemes, the goal is to illustrate how these classes can be represented. Thus, class scheme 1 was called reactive because the items of cooperative professionalism, meritocratic professionalism and appreciation dimensions antagonize (negative correlations) hierarchical rigidity and competition. Hence, the idea of reactivity: individuals in this organizational culture appreciation scheme understand that different professionalism types, as well as employee appreciation and satisfaction, get compromised in situations of greater rigidity and competition, and they react to such conditions. The opposite also happens when individuals understand that there is less rigidity and competition; they show positive attitude towards the two professionalism types and values. Based on the network graph of the reactive scheme class, this outcome is represented by the distance between hierarchical rigidity and competition nodes (Rig code) and the other dimensions. The heat map corroborates this result, since its quadrants mostly showed positive correlation between dimensions such as cooperative and meritocratic professionalism and employee appreciation and satisfaction (bluer shades). On the other hand, hierarchical rigidity and competition presented negative correlation to other dimensions (reddish shades).

The second class was called Resilient Schemes because both cooperative and meritocratic professionalism dimensions tend to have relatively independent relationship with hierarchical rigidity and competition dimensions; some items are even positively correlated to each other. It is possible interpreting that the two professionalism types continue to operate in the same way, regardless of whether the structures of this class are more rigid and the environment is more competitive. Cases where employees are appreciated in a negative way have little to do with hierarchical rigidity and competition. Based on the graph representing the network of resilient schemes, it is possible seeing that this network is more cohesive than that of the previous scheme, whose nodes of the hierarchical rigidity and competition dimension (Rig code) are close to the others, mainly to the nodes of the cooperative (PCoop code) and meritocratic professionalism (PMerit) dimensions. The nodes of the employee appreciation and satisfaction dimension (Value code) are a little farther from the rigidity nodes, since the correlation between these dimensions is negative. The heat map of resilient schemes points toward the same interpretation: correlations between items in professionalism, hierarchical rigidity and competition dimensions tend to be slightly positive (yellow shades) or slightly negative (light red shades). Based on the comparison of correlations between items in the professionalism dimensions and items in the employee appreciation and satisfaction dimension, it is possible seeing that they are clearly less intense (yellower shades) in the class of resilient schemes than in classes of reactive schemes (bluer shades). The difference between classes reinforces the names attributed to each of them: individuals in the class of reactive schemes presented moderately proportional association between professionalism and satisfaction, whereas individuals in the class of resilient schemes presented weak or nonexistent association between these dimensions.

\section{Correlational Classes versus Clusters}

The task of creating correlational classes generates a new nominal variable, in which each observation unit is classified into two, or more, categories. As previously mentioned, 
correlational classes are not clusters. Cluster analysis methods aim at maximizing homogeneity among respondents within each group based on similar answers, whereas correlational classes aim at identifying cases based on two cultural sociology principles (DiMaggio et al., 2018): a) relationality, according to which meanings and attitudes do not emerge from entities in isolation, but from associations between them; and b) multiplicity, which derives from the principle of relationality, according to which respondents are organized into two, or more, groups based on the association of answers given by them.

The current study empirically demonstrated that correlational classes are different from clusters generated through cluster analysis. We used all 47 items in the scale of organizational values to identify homogeneous groups through the hierarchical combination of cases, based on the Euclidean distance, by using the Ward method (see step 6 in the readme.pdf file). Based on the dendrogram analysis (Figure 3), it was possible identifying two different groups, which were corroborated by the scree plot analysis. Next, two groups were generated based on the $K$-means method in order to maximize homogeneity.

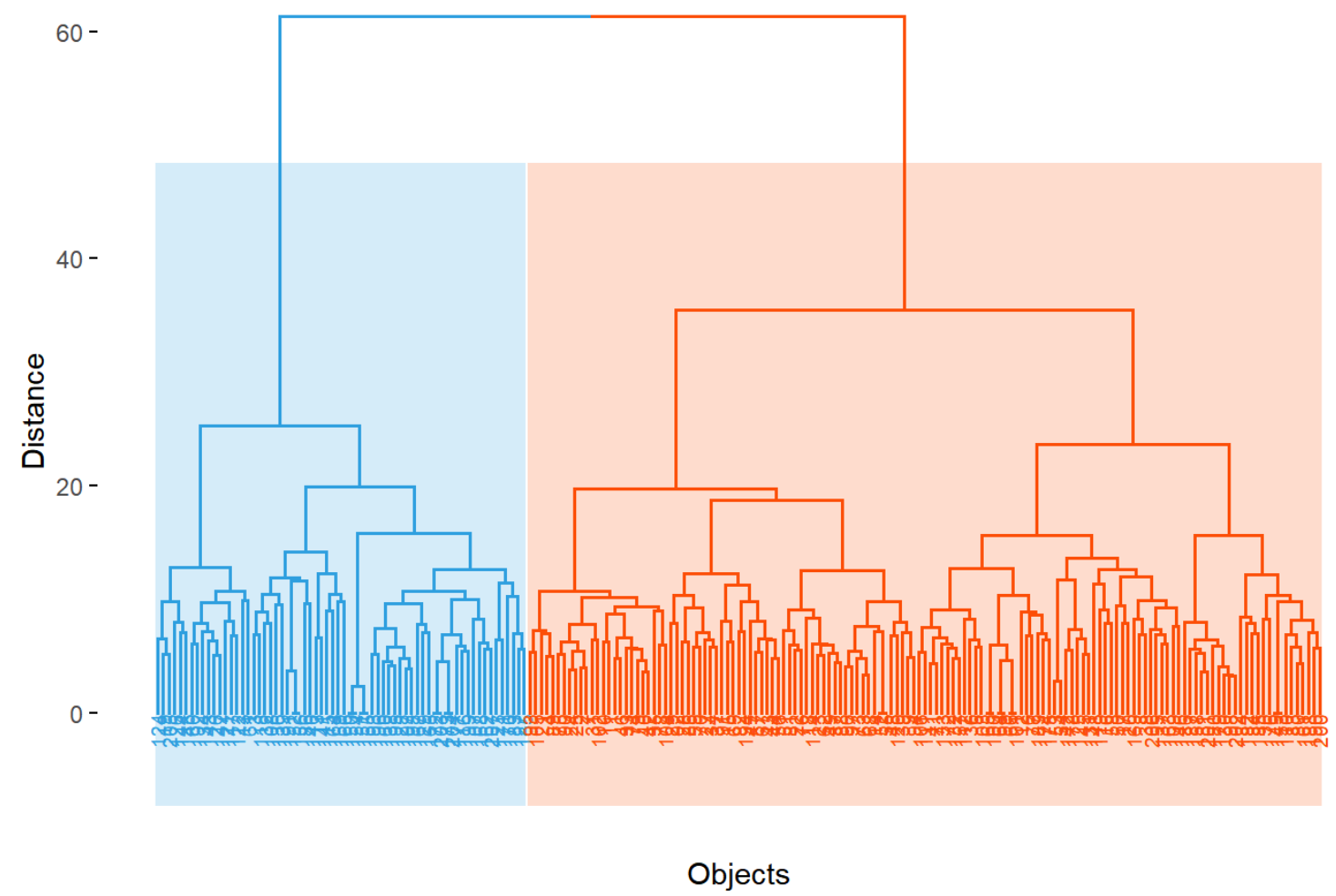

Figure 3 - Identifying Groups based on the Organizational Value Scale

Nominal variables representing the classes were crossed in a crosstab in order to check whether these classes were different from the clusters. It was done by testing differences between categories based on the Chi-square and Cohen's Kappa association tests (see step 7 in the readme.pdf file). Both tests have shown that classes and clusters were significantly different from each other $(p<0.05)$ - Kappa association coefficient was $58.3 \%$, i.e., there was overlap in $58.3 \%$ of cases and disagreement in $41.7 \%$ of them.

In order to assure that differences did not result from the clustering method, the association between correlational classes and clusters generated by another association method - the Two-steps, Schwarz's Bayesian criterion - was tested. Results have indicated that they were significantly different from each other and presented lower association with one another $(K a p p a=52.1 \%)$. Classes and clusters formed from all 4 scale factors were also 
compared to each other. Results have also indicated differences: the Kappa between correlational classes and the cluster generated based on the K-means method was $54.5 \%$, whereas the group generated based on the Two-steps method recorded Kappa equal to $44.2 \%$. These additional analyses were omitted in the readme.pdf file in order to simplify the script in the $R$ software. In short, they pointed out that correlational classes and clusters used empirically different classification criteria.

\section{Using Correlational Classes as Differentiation Schemes}

After all, what are correlational classes used for? Correlational classes allow differentiating individuals in different cultural schemes with different logics of appreciation by preserving cultural multivocality (Goldberg, 2011). Since these classes identify members who share the same meaning structures without necessarily having the same normative position (DiMaggio et al., 2018), the effect of variables affecting attitudes towards organizational culture can change within each class. Thus, correlational classes go beyond cultural differences in terms of positions and capital distribution (Bourdieu, 1984). They also go beyond the difference resulting from the organizational structure (see Hofstede et al., 1990), which treats such aspects as independent variables. Classes and their underlying meaning structures (construals) can also operate as differentiation mechanisms (Goldberg, 2011; DiMaggio \& Goldberg, 2018).

Thus, in order to exemplify such use of correlational classes, two regression models (see step 8 of the readme.pdf file) were run by assuming the employee appreciation and satisfaction dimension as dependent variable. This variable is often used as a partially exogenous element in studies about culture and organizational climate (Geisen et al., 2019), which explains its selection. The other three dimensions of organizational value escalation cooperative professionalism, meritocratic professionalism, hierarchical rigidity and competition - were incorporated as predictors in order to demonstrate how the effect of each dimension can change in each class. Two recurring structural variables investigated in studies on organizational culture (Hofstede et al., 1990; Knoll, Neves, Schyns, \& Meyer, 2020 ) - i.e., the number of employees and company age -, as well as a variable often associated with the best management practices (Bansal \& Clelland, 2004; Raines, 2003) i.e., the ISO 14000 certification - were also adopted in the current study.

Table 2 - OLS Coefficients Between Relational Classes

\begin{tabular}{lcc}
\hline & \multicolumn{2}{c}{ Dependent variable: Employee Satisfaction and Appreciation } \\
\cline { 2 - 3 } & Model (1): Reactive Class & Model (2): Resilient Class \\
\hline Constant & $2.021^{* * *}$ & -0.025 \\
Cooperative Professionalism & $(0.393)$ & $(0.471)$ \\
Hierarchic Rigidity and Competition & $0.264^{* * *}$ & $0.625^{* * *}$ \\
& $(0.080)$ & $(0.139)$ \\
Meritocratic Professionalism & $-0.361^{* * *}$ & $-0.259^{* *}$ \\
Company Age (ln) & $(0.064)$ & $(0.104)$ \\
& $0.341^{* * *}$ & $0.487^{* * *}$ \\
& $(0.073)$ & $(0.123)$ \\
& $0.141^{* * *}$ & -0.039
\end{tabular}




$\begin{array}{lcc}\text { Number of Employees (ln) } & 0.00002 & 0.037 \\ & (0.022) & (0.031) \\ \text { ISO } 14000 & 0.505^{* * *} & 0.141 \\ & (0.125) & (0.202)\end{array}$

\begin{tabular}{lcc}
\hline Observations & 72 & 81 \\
$\mathrm{R}^{2}$ & 0.769 & 0.626 \\
Adjusted $\mathrm{R}^{2}$ & 0.748 & 0.596 \\
Residual Std. Error & $0.362(\mathrm{df}=65)$ & $0.605(\mathrm{df}=74)$ \\
F Statistic & $36.087^{* * *}(\mathrm{~d}=6 ; 65)$ & $20.662^{2 * * *}(\mathrm{df}=6 ; 74)$ \\
\hline
\end{tabular}

Note: ${ }^{*} \mathrm{p}<0.1 ;{ }^{* *} \mathrm{p}<0.05 ;{ }^{* * *} \mathrm{p}<0.01$; Chow test of structural change $(\mathrm{F}=2,322, \mathrm{p}=0,028)$.

Table 2 shows the regression coefficients recorded for both classes, whereas Figure 4 presents the coefficients with the errors. The explanation coefficient was higher in the class of reactive schemes $\left(R^{2}=0.769\right)$ and some coefficients presented differences in the class of resilient schemes. The effect of both professionalism types on the resilient class was stronger than that of hierarchical rigidity and competition. No other variable referring to the organization was significant in the class of resilient schemes, whereas company age $(b=0.141)$ and ISO $14000(b=0.505)$ were significant in the class of reactive schemes.

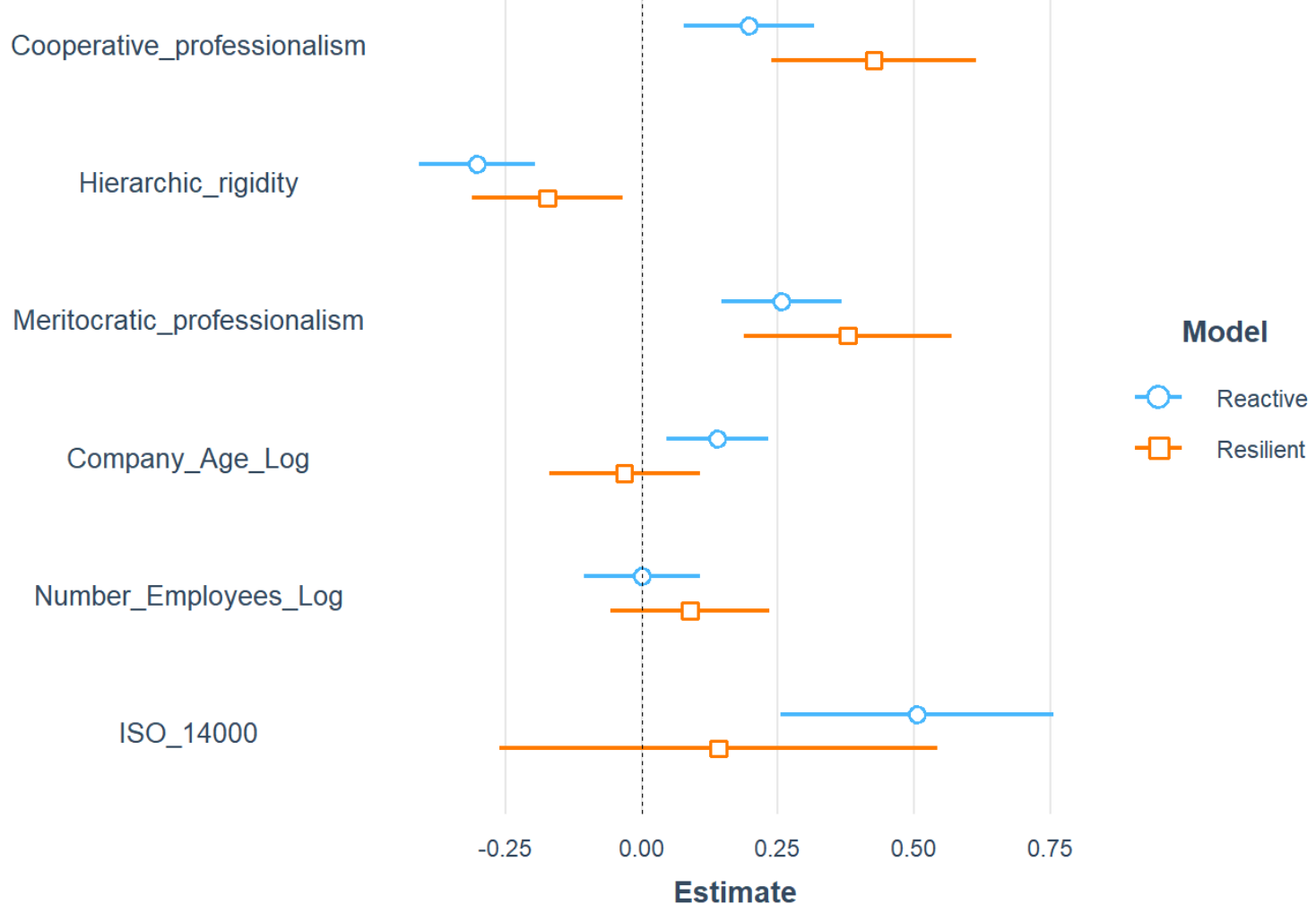

Figure 4 - Coefficients and Standard Error of Regression Models

Each scheme responds to the attitude toward employee appreciation and satisfaction in a different way. Based on the regression coefficients, although reactive schemes strongly react to exogenous aspects linked to the organization - such as rigidity, company age and 
ISO 14000 -, these factors are ignored or have less impact on resilient schemes, since endogenous factors, such as attitudes towards cooperative and meritocratic professionalism, have greater effect on them. This fact was corroborated by the Chow structural change test (Table 2), according to which the two models were structurally different from each other $(p=0.047)$. Actually, reactive schemes reverberated issues associated with the organization, whereas the resilient ones ignored them and focused on internal aspects such as attitude towards professionalism. As previously mentioned, since correlational classes are associated with different cognitive structures, they refer to different ways of appreciating organizational attitude.

\section{Discussion and Conclusion}

Shared cultural schemes have gained prominence in studies about culture (Hunzaker \& Valentino, 2019) and brought sociology and cultural anthropology closer to the cognitive science field (Wood et al., 2018). Despite the importance of such concept, ways of measuring these schemes have always been challenging (Boutyline, 2017), since conventional methods were not capable of capturing them based on two cultural analysis principles, namely: relationality, whose meanings and attitudes do not emerge from entities in isolation, but from associations between them; and multiplicity, according to which respondents organize themselves into two, or more, groups based on simultaneous similarity and divergence patterns between attitudes (DiMaggio et al., 2018). These aspects have been particularly ignored in organizational studies, although studies available in the literature acknowledge that organizational culture manifests itself through shared schemes (Harris, 1994; Langfield-Smith, 1992; Miranda et al., 2015).

In order to fill these gaps, the present tutorial article aimed at introducing the analysis of correlational classes as methodological alternative to map cultural schemes without hurting relationality and multiplicity principles. It exemplified its use based on a survey conducted with 207 workers from different companies, which applied CCA based on organizational value scale adapted to the Brazilian context.

Two different classes were herein identified; they were called reactive and resilient schemes. Although they do not operate as predictor variables, they show different covariance structures between attitudes and allow revealing effects that would be ignored in the full sample (DiMaggio et al., 2018). Based on the herein adopted example, it was possible showing that each class has a different equifinality, i.e., different association paths between organizational variables and attitudes in the analysis of employee appreciation and satisfaction.

Based on CCA, the herein introduced method provided a quantitative way of capturing shared meanings that goes beyond the mere agreement between respondents, something that was already captured through cluster analysis. In fact, new hypotheses can be outlined in the management field, instead of being limited to the study of cultural schemes. Such methods can be used to assess consistency in immaterial elements such as cultures, values, tastes and beliefs, but it can also be used to assess the effects of consistency between material practices and organizational characteristics such as the adoption of practices associated with corporate governance, quality management, market analysis and even analysis of strategic behavior of companies.

It was possible concluding that correlational class analysis (CCA), which is an improved relational class analysis (RCA), uses a new way of analyzing variables in the quantitative research field, since it uses modularity algorithms in networks to evaluate relational patterns between variables, which go beyond the mere similarity of answers. Thus, 
if this method is useful to capture the multivocality of cultural schemes, it can also be useful to capture any class of systemic effect between variables, which refers to a huge field of investigation, whose instrument is described in detail in this tutorial article.

\section{References}

Aktaş, E., Çiçek, I., \& Kıyak, M. (2011). The effect of organizational culture on organizational efficiency: The moderating role of organizational environment and CEO values. Procedia-Social and Behavioral Sciences, 24(2011), 1560-1573.

Baldassarri, D., \& Goldberg, A. (2014). Neither ideologues nor agnostics: Alternative voters' belief system in an age of partisan politics. American Journal of Sociology, 120(1), 45-95.

Bansal, P., \& Clelland, I. (2004). Talking Trash: Legitimacy, Impression Management, and Unsystematic Risk in The Context of The Natural Environment. Academy of Management Journal, 47(1), 93-103.

Barbet, B. (2020). Nobody seems to be fully representing me: Differential inter-attitudinal cohesion systems and their effects on satisfaction with the political system. Electoral Studies, 64, 102116.

Basov, N., \& Brennecke, J. (2017). Structure, Content and Meaning of Organizational Networks: Extending Network Thinking. Research in the Sociology of Organizations, 53, 87-112.

Bourdieu, P. (1984). Distinction: A Social Critique of the Judgement of Taste. Cambridge: Harvard University Press.

Boutyline, A. (2017). Improving the measurement of shared cultural schemas with correlational class analysis: Theory and method. Sociological Science, 4(15), 353-393.

Boutyline, A., \& Vaisey, S. (2017). Belief network analysis: A relational approach to understanding the structure of attitudes. American Journal of Sociology, 122(5), 1371-1447.

Calori, R. \& Sarnin, P. (1991). Corporate culture and economic performance: a French study. Organization Studies, 12(1) 49-74.

Daenekindt, S. (2017). On the structure of dispositions. Transposability of and oppositions between aesthetic dispositions. Poetics, 62, 43-52.

Daenekindt, S. (2019). Out of tune. How people understand social exclusion at concerts. Poetics, 74, 101341.

Daenekindt, S., Koster, W., \& Van der Waal, J. (2017). How people organise cultural attitudes: cultural belief systems and the populist radical right. West European Politics, 40(4), 791-811.

DiMaggio, P. (1997). Culture and Cognition. Annual Review of Sociology, 23, 263-87. 
DiMaggio, P., \& Goldberg, A. (2018). Searching for Homo economicus: Variation in Americans' construals of and attitudes toward markets. European Journal of Sociology, 59(2), 151-189.

DiMaggio, P., Sotoudeh, R., Goldberg, A., \& Shepherd, H. (2018). Culture out of attitudes: Relationality, population heterogeneity and attitudes toward science and religion in the US. Poetics, 68, 31-51.

Emirbayer, M. (1997). Manifesto for a Relational Sociology. American Journal of Sociology, 103(2), 281-317.

Ferreira, M., Assmar, E., Estol, K., Helena, M., \& Cisne, M. (2002). Desenvolvimento de um instrumento brasileiro para avaliação da cultura organizacional. Estudos de Psicologia, 7(2), 271-280.

Garro, L. C. (2000). Remembering what one knows and the construction of the past: A comparison of cultural consensus theory and cultural schema theory. Ethos, 28(3), 275-319.

Geisen, T., Hassler, B., Wagner, S., Buys, N., Randall, C., Harder, H., ... \& Scott, L. (2019). Raising Awareness and Appreciation: Employee Perspectives on Disability Management in Swiss Companies. International Journal of Disability Management, 14(2019), e1.

Goldberg, A. (2011). Mapping shared understandings using relational class analysis: The case of the cultural omnivore reexamined. American Journal of Sociology, 116(5), 13971436.

Gomide, Jr. S., \& Martins, M. (1997). Os Deuses da Administração: construção e validação de quatro escalas para medida de cultura organizacional. Psicologia: Teoria e Pesquisa, 13(3), 311-316.

Hair, Jr. J., Black, W., Babin, B., \& Anderson, R. (2018). Multivariate Data Analysis (8th ed.). Upper Saddle River: Prentice-Hall.

Harris, S. (1994). Organizational Culture and Individual Sensemaking: A Schema-Based Perspective. Organization Science, 5(3), 309-321.

Hofstede, G., Neuijen, B., Ohayv, D., \& Sanders, G. (1990). Measuring organizational cultures: a qualitative and quantitative study across twenty cases. Administrative Science Quarterly, 35 (2), 286-316.

Hunzaker, M., \& Valentino, L. (2019). Mapping Cultural Schemas: From Theory to Method. American Sociological Review, 84(5), 950-981.

Knoll, M., Neves, P., Schyns, B., \& Meyer, B. (2020). A multi-level approach to direct and indirect relationships between organizational voice climate, team manager openness, implicit voice theories, and silence. Applied Psychology, doi: 10.1111/apps.12242.

Langfield-Smith, K. (1992). Exploring the need for a shared cognitive map. Journal of Maanagement Studies, 29(3), 349-368. 
Miranda, S., Kim, I., \& Summers, J. D. (2015). Jamming with Social Media: How Cognitive Structuring of Organizing Vision Facets Affects IT Innovation Diffusion. MIS Quarterly, 39(3), 591-614.

Mohr, J. \& White, H. (2008). How to Model an Institution. Theory and Society, 37, 485-512.

Netemeyer, R., Bearden, W., \& Sharma, S. (2003). Scalling Procedures: Issues and Applications. Thousand Oaks: Sage.

Nunnaly, J. C. (1978). Psychometric Theory. 2. ed. New York: McGraw-Hill.

Oberg, A., Korff, V., \& Powell, W. (2017). Culture and Connectivity Intertwined: Visualizing Organizational Fields as Relational Structures and Meaning Systems. Research in the Sociology of Organizations, 53, 17-47.

Raines, S. (2003). Perceptions of Legitimacy and Efficacy in International Environmental Management Standards: The Impact of the Participation Gap. Global Environmental Politics, 3(3), 47-73.

Rawlings, C., \& Childress, C. (2019). Emergent Meanings: Reconciling Dispositional and Situational Accounts of Meaning-Making from Cultural Objects. American Journal of Sociology, 124(6), 1763-1809.

Schein, E. (1992). Organizational culture and leadership. San Francisco: Jossey-Bass.

Smircich, L. (1983). Concepts of Culture and Organizational Analysis. Administrative Science Quarterly, 28(3), 339-358.

Strauss, C. \& Quinn, N. (1997). A cognitive theory of cultural meaning. Cambridge: Cambridge University Press.

Tamayo, A., \& Gondim, M. (1996). Escala de valores organizacionais. Revista de Administração, 31(2), 62-72.

Wood, M. L., Stoltz, D. S., Van Ness, J., \& Taylor, M. A. (2018). Schemas and frames. Sociological Theory, 36(3), 244-261.

Wu, A. (2014). Ideological polarization over a China-as-superpower mindset: An exploratory charting of belief systems among Chinese Internet users, 20082011. International Journal of Communication, 8(2014), 2650-2679.

Zerubavel, E. (1997). Social Mindscapes: An Invitation to Cognitive Sociology. Cambridge: Harvard Univ. Press. 